\title{
Effects of embryonic exposure to polychlorinated biphenyls on zebrafish skeletal development
}

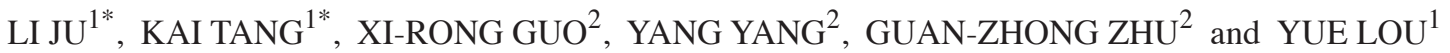 \\ ${ }^{1}$ Department of Pediatric Orthopaedics, Nanjing Children's Hospital of Nanjing Medical University, Nanjing, \\ Jiangsu 210008; ${ }^{2}$ Institute of Pediatrics, Nanjing Medical University, Nanjing, Jiangsu 210029, P.R. China
}

Received December 5, 2011; Accepted February 21, 2012

DOI: $10.3892 / \mathrm{mmr} .2012 .823$

\begin{abstract}
Polychlorinated biphenyls (PCBs) are persistent organic pollutants that affect embryonic development. The purpose of this study was to examine the effects of embryonic exposure to PCBs on early skeletal development in zebrafish (Danio rerio). Zebrafish embryos were immediately exposed to various concentrations $(0,0.125,0.25,0.5$ and $1.0 \mathrm{mg} / \mathrm{l})$ of PCBs (Aroclor 1254) after fertilization. Embryos were assessed at 24, 48, 72, 96 and $120 \mathrm{~h}$ post-fertilization (hpf) for changes in embryonic survival and malformation rates. Calcium content and vitamin D receptor (VDR), parathyroid hormone (PTH) and TRVP6 mRNA expressions were assessed at $120 \mathrm{hpf}$. The results showed that $\mathrm{PCB}$ exposure decreased the survival rate of the embryos in a time-and dose-dependent manner. The embryos exposed to the higher concentrations of PCBs $(0.5$ and $1.0 \mathrm{mg} / \mathrm{l})$ displayed obvious skeletal morphological deformities. At $120 \mathrm{hpf}$, the calcium content of the zebrafish was downregulated in all the PCB-treated groups. VDR, PTH and TRVP6 mRNA expressions were all affected by PCBs. By 120 hpf, the mRNA expressions of VDR, PTH and TRVP6 from the PCB-treated larvae were all upregulated. The expressions of PTH and TRVP6 positively correlated with the level of PCBs to which the embryos were exposed. These results suggest that embryonic exposure to PCBs induces developmental deficits in the zebrafish skeleton.
\end{abstract}

\section{Introduction}

Humans and animals are exposed to persistent organic pollutants, such as furans, dioxins or polychlorinated biphe-

Correspondence to: Professor Yue Lou, Department of Pediatric Orthopaedics, Nanjing Children's Hospital of Nanjing Medical University, No. 72 Guangzhou Road, Nanjing, Jiangsu 210008, P.R. China

E-mail: yuelounjmu@sina.com

*Contributed equally

Key words: polychlorinated biphenyls, Aroclor 1254, zebrafish, spinal deformity, calcium, vitamin D receptor, parathyroid hormone, TRVP6 nyls (PCBs). These compounds accumulate in food chains and are known to affect a series of physiological functions and to disrupt endocrine systems (1-3).

PCBs are persistent organic pollutants found in the environment and in tissue samples (4-6). They are known to cause various adverse effects including endocrine disruptions, carcinogenicity, immune, neural, developmental, reproductive and skeletal toxicity (7-9). Concern over the systemic toxicity of PCBs arose when two tragic episodes occurred in Japan and China (Taiwan) as a result of rice oil being contaminated with PCBs. Thousands of newborns exhibited low birth weight, mucocutaneous pigmentation, periorbital edema, gingival hyperplasia and abnormal skull calcification (10). Thus, PCB exposure seriously affects the development of multiple organs, including the skeleton.

Bone tissue is a specialized connective tissue, which forms the framework of the body. Alterations in bone composition have previously been observed in experimental animals exposed to PCBs (11-16), as well as in natural exposure scenarios in free ranging animals (17). However, none of these experiments or investigations have discussed the toxicity of PCBs during the embryonic developmental period.

Zebrafish (Danio rerio) is a new and popular model due to its fast development, the transparency of its embryos, its ease of manipulation at the molecular level and the availability of various mutants. The simple organization of the zebrafish skeleton and a similar developmental pattern to that of mammals makes zebrafish particularly useful for studies on skeletal development and disease.

The fact that PCB exposure accompanies skeletal deficits supports the need for more extensive studies on the PCB-related effects on the skeleton. The purpose of the present study was to investigate whether the exposure of PCBs during the early-stage of life could affect the development and composition of the zebrafish skeleton.

\section{Materials and methods}

Animal husbandry. Zebrafish were purchased from the Model Animal Research Center of Nanjing University, Tübingen (Germany) strain. The zebrafish were raised and, as adults, were maintained on a 14 -h light $/ 10$-h dark cycle at $28.5^{\circ} \mathrm{C}$; they were bred in tanks as described by Westerfield (18). Fish were fed twice daily with frozen red mosquito larvae from an 
uncontaminated source or, alternatively, with a commercial artificial diet. On the evening before spawning, several Petri dishes were placed at the bottom of the aquaria to collect the eggs. When the light was turned on the following morning, spawning was triggered and completed within $30 \mathrm{~min}$. All animal care and experimental procedures were approved by the Institutional Animal Care and Use Committee, Nanjing Medical University.

Viability and dose-response study. Immediately after fertilization, eggs were randomly distributed into five test groups (90 eggs/group) by placing 15 eggs in each well of a 6-well culture plate. Groups were exposed to $0.125,0.5$ and $1.0 \mathrm{mg} / \mathrm{l}$ $\mathrm{PCB}_{1254}$ (Aroclor 1254, Sigma-Aldrich, Denver, PA, USA) dissolved with $0.01 \%$ methanol into rearing solution within a $100-\mathrm{ml}$ glass Petri dish. The rearing solution contained $0.06 \mathrm{~g}$ $\mathrm{NaCl}$ in $1000 \mathrm{ml}$ of deionized water. Reconstituted water served as the overall control. The effects of each concentration and the controls were studied at five developmental stages [24, 48, 72, 96 and $120 \mathrm{~h}$ post-fertilization (hpf)]. Dishes were covered to prevent the evaporation of PCBs; solutions were changed and degenerating eggs were removed daily. Viability was recorded on the day following exposure, and changes in zebrafish embryo development in each group were observed at x20 magnification under a stereomicroscope at $120 \mathrm{hpf}$.

Measurement of gross calcium. We obtained 50 fish from each group after $120 \mathrm{hpf}$ and rinsed them three times with deionized water. We then added $2.0 \mathrm{ml}$ nitric acid $(2.0 \mathrm{~mol} / \mathrm{l})$ to each sample and placed them under the temperature of $80^{\circ} \mathrm{C}$ for $24 \mathrm{~h}$. Calcium standards 0, 1.0, 2.0, 3.0, 4.0 and $5.0 \mu \mathrm{g} / \mathrm{ml}$ were prepared from calcium standard solution (500 mg/l; Ministry of Environmental Protection) with various amounts of nitric acid $(2.0 \mathrm{~mol} / \mathrm{l})$. We assayed the samples with atomic absorption spectrophotometer AA-6300 (Shimadzu). The instrument settings are summarized as follows: lamp current, $10 \mathrm{Ma}$; wavelength, $422.7 \mathrm{~nm}$; spectral band-width, $0.7 \mathrm{~nm}$; air flow, 15 1/min and acetylen flow, $1.5 \mathrm{l} / \mathrm{min}$.

RNA preparation and quantitative real-time PCR. Total RNA was extracted from 20 fish from each group with TRIzol Reagent (Invitrogen, Carlsbad, CA) according to the manufacturer's instructions. The concentration and purity of isolated RNA were determined by absorbance measures at 260 and $280 \mathrm{~nm}$ in a UV-Visible spectrophotometer (UNIC, China). Its integrity was assessed by $1.0 \%$ agarose gel electrophoresis. The RNA was stored at $-70^{\circ} \mathrm{C}$ until use.

Quantitative real-time PCR was used to determine the relative mRNA levels of vitamin D receptor (VDR), parathyroid hormone (PTH) and TRPV6. First, cDNA was synthesized from $1 \mu \mathrm{g}$ total RNA using random hexamers and reverse transcription reagents (Promega, Madison, WI, USA). Sequence-specific primers and probes for VDR, PTH and TRPV6 (Table I) were designed according to the guidelines for quantitative PCR using Primer Express 3.0 software (Applied Biosystems, Foster City, CA, USA). The quantity of $\beta$-actin was measured as the internal control in all samples. The primers and probe used to measure $\beta$-actin mRNA levels were from Applied Biosystems. The samples were run in duplicate on an ABI Prism 7300 sequence detection system (Applied Biosystems) using the following
Table I. Primers used for mRNA quantification by real-time PCR.

\begin{tabular}{ll}
\hline Gene & Primer $\left(5^{\prime}-3^{\prime}\right)$ \\
\hline VDR & S: CTGGAGGTGTTCGGGAGT \\
& A: TTGCCGCATTGATGTTCT \\
PTH & S: TGAGAAGCAAACGGGCAGTG \\
& A: GCTCCTTGAGTTCGGGAATA \\
TRPV6 & S: TCCTTTCCCATCACCCTC \\
& A: CACTGTGGCAACTTTCGT
\end{tabular}

VDR, vitamin D receptor; PTH, parathyroid hormone; S, Sense; A, Antisense.

cycling parameters: $50^{\circ} \mathrm{C}$ for $2 \mathrm{~min}$ and $95^{\circ} \mathrm{C}$ for $10 \mathrm{~min}$, followed by 45 cycles at $95^{\circ} \mathrm{C}$ for $15 \mathrm{sec}$ and $60^{\circ} \mathrm{C}$ for $1 \mathrm{~min}$. The data were obtained after an analysis of the cycle threshold $(\mathrm{Ct})$ values according to the guidelines of the manufacturer, with the cycle number at which logarithmic PCR plots crossed a calculated threshold line. The mRNA values were depicted as $\Delta \mathrm{Ct}$ values $[\Delta \mathrm{Ct}=\mathrm{Ct}$ of target gene $-\mathrm{Ct}$ of housekeeping gene ( $\beta$-actin) $]$ of each sample. For each experiment, the fold changes of target mRNA under various treatment conditions were calculated by the $2^{-\Delta \Delta \mathrm{Ct}}$ method $(\Delta \Delta \mathrm{Ct}=\Delta \mathrm{Ct}$ of treatment groups gene $-\Delta \mathrm{Ct}$ of control group gene) (19).

Statistical analysis. Statistical analyses were performed using the $\chi^{2}$ test for categorical data, or a one-way analysis of variance (ANOVA) for analysis of the measurement data. The doseresponse relationship was analyzed by the Mantel-Haenszel test. Differences were considered significant at $\mathrm{P}<0.05$.

\section{Results}

Spinal deformity and viability. The spinal deformity rates of the zebrafish exposed to $0.125 \mathrm{mg} / \mathrm{PCB}_{1254}$ were infrequent, while at 0.5 and $1.0 \mathrm{mg} / 1$, the numbers of larvae with spinal deformities increased significantly after $72 \mathrm{hpf}$. Exposure to $1.0 \mathrm{mg} / 1 \mathrm{PCB}_{1254}$, however, increased the percentage of deformed larvae to $37.8 \%$ at $120 \mathrm{hpf}$ (Fig. 1). Survival rates after $120 \mathrm{hpf}$ were $97.8,100,94.4,58.9$ and $41.1 \%$ for the control, $0.01 \%$ methanol, $0.125,0.5$ and $1.0 \mathrm{mg} / \mathrm{PCB}_{1254}$ treatments, respectively (Table II). With the concentration and time increase, the survival rate declined, while the malformation rate increased significantly (Table II), indicating a specific time-and dose-dependent effect.

Measurement of gross calcium. The linear regression equation of calcium to the absorbance was calculated according to the calcium standard solution. The calcium concentration of each group was calculated according to the formula: $\mathrm{Abs}=0.05041$ 0Conc $+0.00183000, r=0.9993$, where Abs is the absorbance, Conc is the concentration of calcium and $r$ is the correlation co-efficient (Table III). Compared to the control group, a normal level of total calcium was detected in the methanol group while significantly decreased levels of total calcium were found in the $0.125,0.5$ and $1.0 \mathrm{mg} / \mathrm{l}$ groups (Fig. 2). 
Table II. Effect of $\mathrm{PCB}_{1254}$ exposure on survival and deformity rate of zebrafish embryos.

\begin{tabular}{|c|c|c|c|c|c|c|}
\hline \multirow{2}{*}{$\begin{array}{l}\text { Various } \\
\text { concentration } \\
\text { groups }\end{array}$} & \multicolumn{6}{|c|}{ Time (hpf) } \\
\hline & 0 & 24 & 48 & 72 & 96 & 120 \\
\hline \multicolumn{7}{|l|}{ Control } \\
\hline Survival (rate \%) & 90 & $88(97.8)$ & $88(97.8)$ & $88(97.8)$ & $88(97.8)$ & $88(97.8)$ \\
\hline Malformation (rate \%) & 0 & $0(0)$ & $0(0)$ & $2(2.2)$ & $2(2.2)$ & $2(2.2)$ \\
\hline \multicolumn{7}{|l|}{$0.01 \%$ Methanol } \\
\hline Survival (rate \%) & 90 & $90(100)$ & $90(100)$ & $90(100)$ & $90(100)$ & $90(100)$ \\
\hline Malformation (rate \%) & 0 & $0(0)$ & $0(0)$ & $2(2.2)$ & $2(2.2)$ & $2(2.2)$ \\
\hline \multicolumn{7}{|l|}{$0.125 \mathrm{mg} / 1$} \\
\hline Survival (rate \%) & 90 & $88(97.8)$ & $85(94.4)$ & $85(94.4)$ & $85(94.4)$ & $85(94.4)$ \\
\hline Malformation (rate \%) & 0 & $0(0)$ & $0(0)$ & $3(3.3)$ & $4(4.4)$ & $4(4.4)$ \\
\hline \multicolumn{7}{|l|}{$0.5 \mathrm{mg} / 1$} \\
\hline Survival (rate \%) & 90 & $90(90.0)$ & $85(94.4)$ & $81(90)^{\mathrm{a}}$ & $67(74.4)^{\mathrm{a}}$ & $53(58.9)^{\mathrm{a}}$ \\
\hline Malformation (rate \%) & 0 & $0(0)$ & $0(0)$ & $4(4.4)$ & $11(12.2)^{\mathrm{a}}$ & $14(15.6)^{\mathrm{a}}$ \\
\hline \multicolumn{7}{|l|}{$1.0 \mathrm{mg} / \mathrm{l}$} \\
\hline Survival (rate \%) & 90 & $90(90.0)$ & $75(83.3)^{\mathrm{a}}$ & $67(74.4)^{\mathrm{a}}$ & $51(56.7)^{\mathrm{a}}$ & $37(41.1)^{\mathrm{a}}$ \\
\hline Malformation (rate \%) & 0 & $0(0)$ & $0(0)$ & $11(12.2)^{\mathrm{a}}$ & $26(28.9)^{\mathrm{a}}$ & $34(37.8)^{\mathrm{a}}$ \\
\hline
\end{tabular}

${ }^{\mathrm{a} C o m p a r e d}$ with the normal control group $\mathrm{P}<0.05$. hpf, hours post-fertilization.

Table III. Absorbance and calcium concentration of each sample.

\begin{tabular}{lccc}
\hline & Concentration determination & $\begin{array}{c}\text { Absorbance } \\
(\mathrm{nm})\end{array}$ \\
\cline { 2 - 3 } & $\mu \mathrm{g} / \mathrm{ml}$ & $\mu \mathrm{g} / 50 \mathrm{fish}$ & \\
\hline Sample blank & 0 & 0 & 0.0039 \\
Normal-1 & 2.1520 & 10.76 & 0.1103 \\
Normal-2 & 2.4141 & 12.07 & 0.1235 \\
Normal-3 & 2.3564 & 11.78 & 0.1206 \\
Methanol-1 & 2.3643 & 11.82 & 0.1210 \\
Methanol-2 & 2.3603 & 11.80 & 0.1208 \\
Methanol-3 & 2.1232 & 10.62 & 0.1089 \\
$0.125 \mathrm{mg} / \mathrm{l}-1$ & 2.0026 & 10.01 & 0.1028 \\
$0.125 \mathrm{mg} / \mathrm{l}-2$ & 2.0406 & 10.20 & 0.1047 \\
$0.125 \mathrm{mg} / \mathrm{l}-3$ & 2.0472 & 10.24 & 0.1050 \\
$0.5 \mathrm{mg} / \mathrm{l}-1$ & 1.7943 & 8.97 & 0.0923 \\
$0.5 \mathrm{mg} / \mathrm{l}-2$ & 1.7560 & 8.78 & 0.0903 \\
$0.5 \mathrm{mg} / \mathrm{l}-3$ & 1.6513 & 8.26 & 0.0851 \\
$1.0 \mathrm{mg} / \mathrm{l}-1$ & 1.8293 & 9.15 & 0.0940 \\
$1.0 \mathrm{mg} / \mathrm{l}-2$ & 1.7335 & 8.67 & 0.0892 \\
$1.0 \mathrm{mg} / \mathrm{l}-3$ & 1.6118 & 8.06 & 0.0831 \\
\hline
\end{tabular}

Effects of A1254 on VDR, PTH and TRVP6 mRNA expression. As shown in Fig. 3, VDR, PTH and TRVP6 mRNA expressions were all affected by $\mathrm{PCB}_{1254}$. By $120 \mathrm{hpf}$, the mRNA expressions of VDR, PTH and TRVP6 from the PCB-treated larvae were all upregulated. The expressions of PTH and TRVP6 positively correlated with the level of $\mathrm{PCB}_{1254}$ to which the embryos were exposed.
$\mathbf{A}$

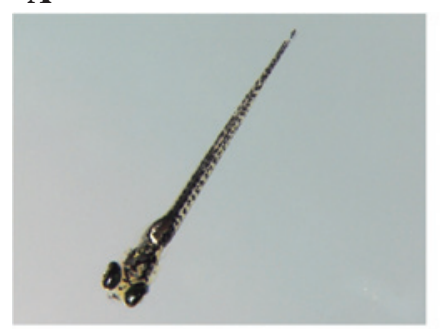

C

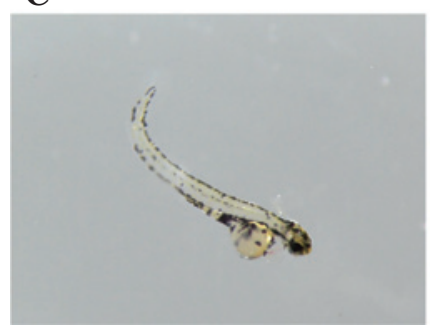

B

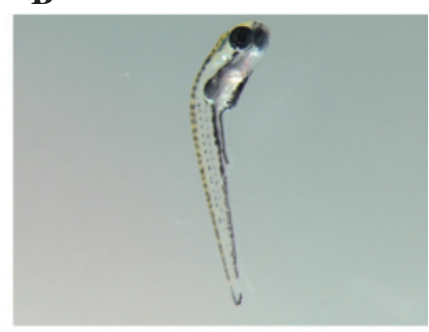

D

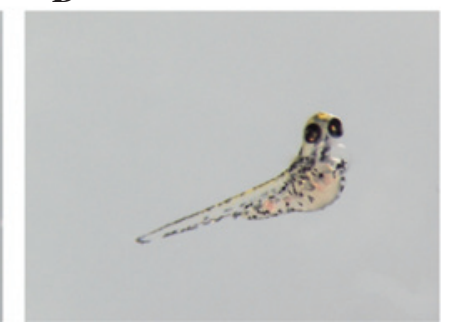

Figure 1. Phenotypic appearance of embryonic zebrafish exposed to various concentrations of polychlorinated biphenyls (PCBs): control, $0.01 \%$ methanol, $0.125,0.5$ and $1.0 \mathrm{mg} / \mathrm{l}$ PCBs (Aroclor 1254) $120 \mathrm{~h}$ post-fertilization, $\mathrm{x} 20$. (A) Most of the larvae in the control, methanol and $0.125 \mathrm{mg} / \mathrm{l} \mathrm{PCB}$ groups have a normal appearance, whereas (B-D) larvae exposed to higher PCB concentrations $(0.5$ and $1.0 \mathrm{mg} / \mathrm{l})$ have abnormal curly spondyles.

\section{Discusssion}

The mechanisms underlying the development of the skeleton are not clearly understood, mainly as the ability to study the dynamic processes of giving rise to cartilage and bone in living embryos has been limited. The zebrafish is an ideal model organism for studying skeletal development, as the embryos 
Total calcium after $120 \mathrm{hpf}$

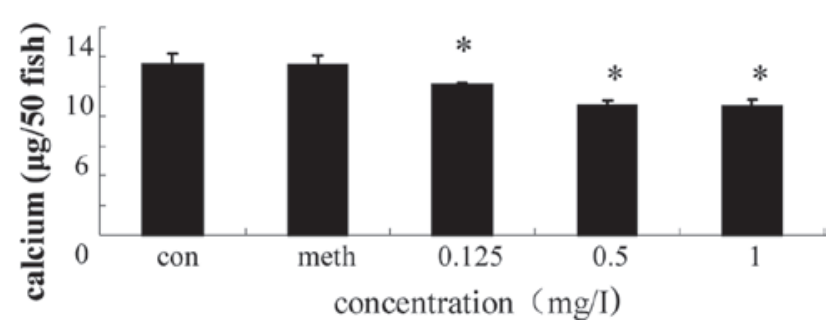

Figure 2. Effect of polychlorinated biphenyl (PCB) (Aroclor 1254) exposure on calcium concentration of zebrafish embryos. ${ }^{*}$ Compared with the normal control group $\mathrm{P}<0.05$; bars represent the means $\pm \mathrm{SE}$. hpf, hours post-fertilization; con, control; meth, methanol.

and larvae are small and transparent, enabling the study of organogenesis in the living organism. Zebrafish cartilage and bone elements develop early and have distinct morphologies, and the genetic mechanisms underlying skeletal formation are shared with other vertebrates (20).

The results of the present study demonstrate that the developing zebrafish is sensitive to pharmacologically relevant doses of PCBs. Zebrafish exposed to moderate-to-high levels of PCBs during the early developmental stage exhibited increased mortality and malformations, such as pericardial edema, yolk sac edema and body bending. Similar findings in zebrafish and other animal studies have been previously reported, including decreased viability and pericardial edema in zebrafish $(21,22)$, as well as an increase in the numbers and the identification of patterns of malformation in Japanese medaka (23) and amphibians (24).

The skeleton of zebrafish develops as early as two days post-fertilization (dpf) and has a fully functional cartilaginous skeleton by five dpf (25). As zebrafish grow and develop, calcium is the most abundant mineral found in their bodies, with $99 \%$ of the total calcium being found in the bones and teeth. Our study showed that at $120 \mathrm{hpf}$, the calcium of the PCB-treated larvae decreased significantly. The loss of calcium suggests that developmental exposure to $\mathrm{PCB}_{1254}$ may interfere with the metabolism of calcium. The PCB-induced toxicity is mediated by the increased production of ROS. The uncontrolled availability of ROS induces excess production of cytokines, such as IL-1, IL- 6 and TNF- $\alpha$ which promote osteoclastic function and bone resorption (26). This correlates with the decreased bone length, bone strength and altered metabolic activity in rats $(13,16,27)$. Therefore, we hypothesized that $\mathrm{PCB}_{1254}$ can promote bone resorption and cause a loss of calcium which is similar to osteoporosis.

VDR is the central mediator of the cellular effects of vitamin $\mathrm{D}$ with the natural occurring ligand being $1,25(\mathrm{OH})_{2} \mathrm{D}_{3}$. Target cells, located throughout the body, have VDRs that bind circulating $1,25(\mathrm{OH})_{2} \mathrm{D}_{3}$. PTH is an 84 -amino acid protein that is secreted by parathyroid glands in response to low serum calcium. Elevated levels of calcium and vitamin D provide negative feedback inhibition of PTH and VDR. TRPV6 has been described in intestinal epithelial cells to selectively transport $\mathrm{Ca}^{2+}(28)$. It is a member of the transient receptor potential channel superfamily (29) and is considered to be the gatekeeper of selective $\mathrm{Ca}^{2+}$ absorption in the small intestine (30,31). These

\section{VDR expression after $120 \mathrm{hpf}$}

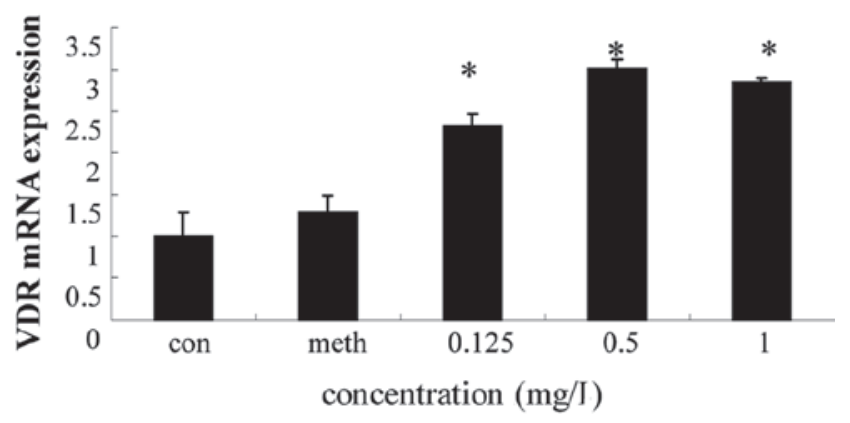

PTH expression after $120 \mathrm{hpf}$

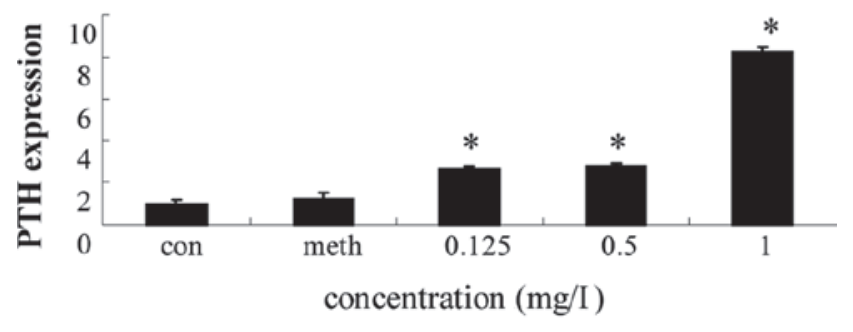

TRPV6 expression after $120 \mathrm{hpf}$

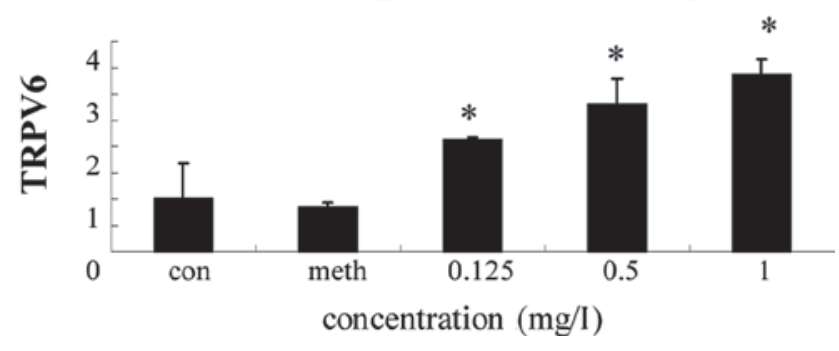

Figure 3. Effect of polychlorinated biphenyl (PCB) (Aroclor 1254) exposure on vitamin D receptor (VDR), parathyroid hormone (PTH) and TRPV6 mRNA expressions in zebrafish embryos. "Compared with the normal control group $\mathrm{P}<0.05$; bars represent the means $\pm \mathrm{SE}$. hpf, hours post-fertilization; con, control; meth, methanol.

three genes are indispensable in the possession of mineralization. The water used in our experiment was purified without any ion including $\mathrm{Ca}^{2+}$, so the lavae could not absorb any calcium from the environment. ROS produced by $\mathrm{PCB}_{1254}$ is believed to induce bone-related diseases by suppressing bone formation and stimulating bone resorption. As VDR, PTH and TRPV6 are sensitive to calcium, their upreguation suggests that the body was performing a compensatory reaction to maintain the calcium at a normal level.

In conclusion, the findings from our study demonstrate that PCBs (Aroclor 1254) have adverse effects on the viability and malformation rate of developing zebrafish embryos and affect the zebrafish calcium metabolism. The investigation of the typical drinking water sources in the Jiangsu Province of China found that the concentration of PCBs is far beyond the WHO standards (32). This suggests the importance of monitoring PCBs in our environment and evaluating their skeletal toxicity in wildlife. 


\section{Acknowledgements}

The authors thank Professor Yue Lou and Xi-Rong Guo for their comments and guidance.

\section{References}

1. Brouwer A, Morse DC, Lans MC, Schuur GA, Murk AJ, Klasson-Wehler E, Bergman $\AA$ and Visser TJ: Interactions of persistent environmental organohalogens with the thyroid hormones system: mechanisms and possible consequences for animal and human health. Toxicol Ind Health 14: 59-84, 1998.

2. Lilienthal H, Hack A, Roth-Härer A, Grande SW and Talsness C: Effects of developmental exposure to 2,2',4,4',5-pentabromodiphenyl ether (PBDE-99) on sex steroids, sexual development, and sexually dimorphic behavior in rats. Environ Health Perspect 114: 194-201, 2006

3. Gutleb AC, Schriks M, Mossink L, Berg JH and Murk AJ: A synchronized amphibian metamorphosis assay as an improved tool to detect thyroid hormone disturbance by endocrine disruptors and apolar sediment extracts. Chemosphere 70: 93-100, 2007.

4. Chan K, Lehmler HJ, Sivagnanam M, Feng CY, Robertson L and O'Brien PJ: Cytotoxic effects of polychlorinated biphenyl hydroquinone metabolites in rat hepatocytes. J Appl Toxicol 30 163-171, 2010

5. Tilson HA and Kodavanti PR: Neurochemical effects of polychlorinated biphenyls: an overview and identification of research needs. Neurotoxicology 18: 727-743, 1997.

6. Tilson HA, Jacobson JL and Rogan WJ: Polychlorinated biphenyls and the developing nervous system: cross-species comparison. Neurotoxicol Teratol 12: 239-248, 1990.

7. Kimbrough RD and Krouskas CA: Human exposure to polychlorinated biphenyls and health effects: a critical synopsis. Toxicol Rev 22: 217-233, 2003.

8. Ulbrich B and Stahlmann R: Developmental toxicity of polychlorinated biphenyls (PCBs): a systematic review of experimental data. Arch Toxicol 78: 252-268, 2004

9. Lundberg R, Lyche JL, Ropstad E, Aleksandersen M, Rönn M, Skaare JU, Larsson S, Örberg J and Lind PM: Perinatal exposure to PCB 153, but not PCB 126, alters bone tissue composition in female goat offspring. Toxicology 10: 33-40, 2006.

10. Furue M, Uenotsuchi T, Urabe K, Ishikawa T and Kuwabara M: Overview of Yusho. J Dermatol Sci (Suppl 1): S3-S10, 2005.

11. Lind PM, Eriksen EF, Sahlin L, Edlund M and Örberg J: Effects of antiestrogenic environmental pollutant 3,3',4,4',5-pentachlorobiphenyl (PCB 126) in rat bone and uterus: diverging effects in ovariectomized and intact animals. Toxicol Appl Pharmacol 154: 236-244, 1999

12. Lind PM, Larsson S, Johansson S, Melhus H, Wikstrom M, Lindhe Ö and Örberg J: Bone tissue composition, dimensions and strength in female rats given an increased dietary level of vitamin A or exposed to 3,3',4,4',5-pentachlorobiphenyl (PCB 126) alone or in combination with vitamin C. Toxicology 151: 11-23, 2000

13. Lind PM, Erikssen EF, Lind L, Örberg J and Sahlin L: Estrogen supplementation modulates effects of the endocrine disrupting pollutant PCB 126 in rat bone and uterus: diverging effects in ovariectomized and intact animals. Toxicology 199: 129-136, 2004.

14. Ramajayam G, Sridhar M, Karthikeyan S, Lavanya R, Veni S, Vignesh RC, Ilangovan R, Djody SS, Gopalakrishnan V, Arunakaran J and Srinivasan N: Effect of Aroclor 1254 on femoral bone metabolism in adult male Wistar rats. Toxicology 241: 99-105, 2007.
15. Yilmaz B, Seyran AD, Sandal S, Aydin M, Colakoglu N, Kocer M and Carpenter DO: Modulatory effects of Aroclors 1221 and 1254 on bone turnover and vertebral histology in intact and ovariectomized rats. Toxicol Lett 166: 276-284, 2006.

16. Alvarez-Lloret P, Lind PM, Nyberg I, Orberg J and RodríguezNavarro AB: Effects of 3,3',4,4',5-pentachlorobiphenyl (PCB 126) on vertebral bone mineralization and on thyroxin and vitamin D levels in Sprague-Dawley rats. Toxicol Lett 187: 63-68, 2009.

17. Lind PM, Bergman A, Olsson M and Örberg J: Bone mineral density in male Baltic grey seals (Halichoerus grypus). Ambio 32: 385-388, 2003

18. Westerfield M: The Zebrafish Book: A Guide for the Laboratory Use of Zebrafish (Danio rerio). 4th edition. University of Oregon Press, Eugene, OR, 1993.

19. Bujalska IJ, Quinkler M, Tomlinson JW, Montague CT, Smith DM and Stewart PM: Expression profiling of 11 $\beta$-hydroxysteroid dehydrogenase type-1 and glucocorticoid-target genes in subcutaneous and omental human preadipocytes. J Mol Endocrinol 37: 327-340, 2006

20. Yelick PC and Schilling TF: Molecular dissection of craniofacial development using zebrafish. Crit Rev Oral Biol Med 13: 308-322, 2002

21. Sisman T, Geyikoglu F and Atamanalp M: Early life-stage toxicity in zebrafish (Danio rerio) following embryonal exposure to selected polychlorinated biphenyls. Toxicol Ind Health 23: 529-536, 2007.

22. Billsson K, Westerlund L, Tysklind M and Olsson P: Developmental disturbances caused by polychlorinated biphenyls in zebrafish (Brachydanio rerio). Mar Environ Res 46: 461-464, 1998.

23. Kim Y and Cooper KR: Toxicity of 2,3,7,8-tetrachlorodibenzop-dioxin (TCDD) and polychlorinated biphenyls (PCBs) in the embryos and newly hatched larvae of the Japanese Medaka (Oryzias latipes). Chemosphere 39: 527-538, 1999.

24. Gutleb AC, Appelman J, Bronkhorst MC, van den Berg JH, Spenkelink A, Brouwer A and Murk AJ: Delayed effects of pre-and early-life time exposure to polychlorinated biphenyls on tadpoles of two amphibian species (Xenopus laevis and Rana temporaria). Environ Toxicol Pharmacol 8: 1-14, 1999.

25. Schilling TF and Kimmel CB: Musculoskeletal patterning in the pharyngeal segments of the zebrafish embryo. Development 124 : 2945-2960, 1997.

26. Jagger CJ, Lean JM, Davies JT and Chambers TJ: Tumor necrosis factor-alpha mediates osteopenia caused by depletion of antioxidants. Endocrinology 146: 113-118, 2005.

27. Andrews JE: Polychlorinated biphenyl (Aroclor 1254) induced changes in femur morphometry calcium metabolism and nephrotoxicity. Toxicology 57: 83-96, 1989.

28. Zhuang L, Peng JB, Tou L, Takanaga H, Adam RM, Hediger MA and Freeman MR: Calcium-selective ion channel, CaT1, is apically localized in gastrointestinal tract epithelia and is aberrantly expressed in human malignancies. Lab Invest 82: $1755-1764,2006$

29. Montell C: Physiology, phylogeny, and functions of the TRP superfamily of cation channels. Sci STKE: re1, 2001.

30. van de Graaf SF, Boullart I, Hoenderop JG and Bindels RJ: Regulation of the epithelial $\mathrm{Ca}^{2+}$ channels TRPV5 and TRPV6 by lalpha,25-dihydroxy Vitamin D3 and dietary $\mathrm{Ca}^{2+}$. J Steroid Biochem Mol Biol 89-90: 303-308, 2004.

31. Van Cromphaut SJ, Dewerchin M, Hoenderop JG, Stockmans I, Van Herck E, Kato S, Bindels RJ, Collen D, Carmeliet P, Bouillon R and Carmeliet G: Duodenal calcium absorption in vitamin D receptor-knockout mice: functional and molecular aspects. Proc Natl Acad Sci USA 98: 13324-13329, 2001.

32. Ye $\mathrm{H}$, Zhou $\mathrm{CH}$ and Zeng XX: Investigation of pollution characteristics of polychlorinated biphenyls in the typical drinking water sources in Jiangsu Province, China. Environ Monit Assess 158: 573-579, 2009. 